\title{
Special Issue on Autonomous Robot Systems
}

\author{
Luís Paulo Reis • João M. Ferreira Calado • \\ Rui Paulo Rocha
}

Published online: 11 October 2014

(C) Springer Science+Business Media Dordrecht 2014

This special issue includes extended versions of selected papers presented in the 13th International Conference on Autonomous Robot Systems (Robotica 2013), held in Lisbon, Portugal, on April $24^{\text {th }} 2013$, an international event co-sponsored by IEEE Robotics and Autonomous Society and organized by the Portuguese Society for Robotics together with the Portuguese Robotics Open.

The conference had a keynote by Prof. Wolfram Burgard from the Department of Computer Science of Freiburg University, Germany, and aimed at disseminating the most advanced knowledge and promoting discussion of theories, methods and experiences in areas of relevance to the knowledge domains of Mobile Robotics and Robotic Competitions.

A total of 37 papers were submitted in response to the call for papers of Robotica 2013. After a double blind review process with at least three reviewers

L. P. Reis $(\bowtie)$

University of Minho, Guimarães, Portugal

e-mail: lpreis@dsi.uminho.pt

J. M. Ferreira Calado

Polytechnic Institute of Lisbon, Lisbon, Portugal

e-mail: jcalado@dem.isel.ipl.pt

R. P. Rocha

University of Coimbra, Coimbra, Portugal

e-mail: rui.rocha@uc.pt per paper, 13 papers were accepted as regular papers for oral presentation and 9 papers were accepted for a short presentation plus poster presentation.

The authors of the 12 best papers presented in the conference were invited to submit an extended version to this special issue on Autonomous Robot Systems of the Journal of Intelligent \& Robotic Systems. The authors were required to extend their papers presented in the conference with at least $30 \%$ of new content.

After a rigorous review process of every submitted paper by three to four specialized reviewers per paper, finally 9 papers were accepted to be published in this special issue, covering interesting and up-to-date research topics on Autonomous Robot Systems, including human-machine interaction, ultrasound guided surgery, mobile robot localization, odometry from stereo vision, educational mobile robots, inverse kinematics of a humanoid robot, and anomaly detection in robot behaviors.

We thank all authors for their contributions and all reviewers for their insightful and thorough reviews during the review process of this special issue.

\section{The Guest Editors}

Luís Paulo Reis

João M. Ferreira Calado

Rui Paulo Rocha 